\title{
ANÁLISE DE REDES SOCIAIS: ESTUDO DA REDE DE STARTUPS SAN PEDRO VALLEY
}

Nair Aparecida De Andrade ${ }^{1}$

Gustavo Rodrigues Cunha ${ }^{2}$

Vanuza Bastos Rodrigues ${ }^{3}$

${ }^{1}$ Centro Universitário Unihorizontes

${ }^{2}$ Centro Unversitário Unihorizontes / UNIHORIZONTES

${ }^{3}$ Universidade Anhembi Morumbi 


\section{ANÁLISE DE REDES SOCIAIS: ESTUDO DA REDE DE STARTUPS SAN PEDRO VALLEY}

Resumo: O presente estudo teve por objetivo descrever e analisar a rede social formada pela comunidade San Pedro Valley, ecossistema de inovação composto por 315 organizações, buscando compreender as dinâmicas desenvolvidas entre os membros da rede em termos de contatos, informação, confiança, aconselhamento, capacitação, cooperação/parceria. Os resultados indicam uma rede relativamente ampla, mas com baixa densidade e com um número elevado de atores periféricos sem conexão com o núcleo central. Neste sentido, embora a San Pedro Valley tenha como visão promover a inovação e o empreendedorismo, o baixo índice de densidade conduz a uma lacuna entre a proposição e a prática, indicando concentração de relações, poder e influência entre poucas organizações, algumas destas não participantes da rede formal.

Palavras-chave: Ecossistemas empreendedores. Redes sociais. Inovação. Startups

\section{$1 \quad$ Introdução}

O empreendedorismo e a inovação expressam-se de maneira profícua, dentre outras formas, por meio dos modelos organizacionais, os quais exercem papel fundamental nos processos de geração de riqueza, inserção em novos mercados, ganhos de produtividade e melhoria ou incorporação de tecnologias para a obtenção de vantagens estratégicas (Ikenami, Garnica, \& Ringer, 2016).

Os empreendimentos, por vezes, se amparam em instrumentos como os ecossistemas empreendedores ou as redes sociais, de modo a fortalecer as competências gerenciais e produtivas. Tais recursos vêm se consolidando como paradigma na busca de alternativas viáveis para a condução estruturada dos negócios. Todavia, tais perspectivas pressupõem conectividade, cooperação e interdependência, em que aspectos cognitivos se fazem presentes, os quais perpassam as dimensões atitudinal e relacional do empreendedor.

À luz de Castells (1999), a adoção pelas organizações do mecanismo de redes torna-se uma ferramenta de apoio à inovação e à competitividade, tendo em vista a globalização da economia e a gestão do conhecimento. $\mathrm{O}$ autor enxerga as redes sociais como instrumento fundamental para as organizações, na medida em que propicia sua inserção e expansão em contextos mercadológicos ampliados, gerando o compartilhamento de informações, conhecimentos e decisões.

Entretanto, percebe-se que os empreendimentos ancorados em inovação, principalmente em sua fase nascente, têm dificuldades para agregar valor a seus produtos e para manterem uma constância nesse processo inovativo, promovendo insustentabilidade ao longo do tempo. Esse resultado ocorre devido, de um lado à ineficiência produtiva e à inadequação das estratégias gerenciais engendradas, de outro, a um ambiente institucional desfavorável ao desenvolvimento de iniciativas empreendedoras que, no caso do Brasil, se traduzem em: excesso de burocracia, políticas tributárias pouco compensatórias, infraestrutura deficiente e ausência de apoio técnico-financeiro (Barbieri, 2003; Isenberg, 2010).

Além das iniciativas de âmbito governamental que venha a favorecer o ambiente de negócios, são imperativos ao sucesso empresarial: aquisição de competências e de recursos de 
cunho empresarial que propiciem flexibilidade; múltiplas interações e compartilhamentos de aprendizados; e iniciativas que permitam o encadeamento do processo produtivo (Balestrin \& Verschoore, 2008; Faccin \& Brand, 2015; Ikenami \& Garnica, 2016).

$\mathrm{O}$ processo bem-sucedido de organização em rede pressupõe o fortalecimento de atributos como confiança, parceria, cooperação e/ou aliança e conhecimento entre seus integrantes em prol de objetivos comuns. A expectativa é que uma rede social possa gerar, dentre outros outputs, elementos como contatos, informação, aconselhamento, capacitação e contribuição ao processo decisório (Castells, 1999; Silva, 2012).

Em 2011, criou-se em Belo Horizonte a San Pedro Valley, uma rede social de fomento à inovação compostas por 315 organizações, distribuídas nas seguintes categorias: duas incubadoras, 10 espaços de coworking, oito aceleradoras, 37 agências digitais; um Hackerspace; cinco investidores e 252 startups, cujo objetivo é identificar oportunidades, necessidades e incentivos ao segmento.

Nesse sentido, o problema de pesquisa analisado neste artigo busca responder: Como se configura a estrutura da rede social de fomento à inovação denominada San Pedro Valley, na percepção dos gestores das empresas que a integram?

Para encontrar respostas a esse problema, a investigação objetivou identificar a percepção dos gestores das organizações componentes do ecossistema empreendedor San Pedro Valley sobre a rede social no que se refere aos fatores relacionados a: contatos, cooperação/parceria e/ou aliança, confiança, busca por informações, aconselhamento, capacitação (mentoring e consultoria) e atores-chave do seu processo de desenvolvimento, além de dimensionar a centralização e densidade de tais atributos no âmbito da referida rede.

\section{A San Pedro Valley como estratégia de desenvolvimento da inovação empreendedora}

A pesquisa contemplou organizações integrantes da comunidade empreendedora San Pedro Valley, caracterizada como um ecossistema empreendedor digital, cujas informações retiradas do seu site em 24 de abril 2017 relatam que ela surgiu no bairro de São Pedro, em Belo Horizonte, Minas Gerais, durante encontros informais dos empreendedores e tem se posicionado como um dos mais importantes centros de startups do Brasil. O objetivo da rede é integrar empresas com vistas à identificação de oportunidades, necessidades e incentivos de modo a encontrar respostas ao avanço da fronteira do conhecimento e ao fortalecimento do empreendedorismo e da competitividade (San Pedro Valley, 2016).

As redes sociais traduzem, em certa medida, a estrutura das relações dos indivíduos na sociedade. Tais relações estão imbricadas em um fluxo constante de troca de recursos. Sua eficácia depende da intensidade e da proporção dos laços que se estabelecem no decorrer dessas conexões. Vale dizer que essas conexões podem assumir um cunho estrutural, quando vistas a partir do posicionamento dos integrantes na rede, ou relacional, quando o comportamento dos agentes é dependente das expectativas e da coesão do grupo (Granovetter, 1992,1994).

A obtenção de informações estratégicas sobre ampliação dos conhecimentos, difusão tecnológica e busca de mentoria pelos empreendedores em rede é altamente dependente da qualidade dessas conexões, podendo estas serem diretas ou indiretas. Quanto mais direto o envolvimento do empreendedor com a rede, mais recursos ele terá para aproveitar as oportunidades empreendedoras e gerar novas ideias. Daí, conclui-se que a rede social tem 
papel crucial no processo de desenvolvimento econômico, na medida em que os contatos, fruto da confiança estabelecida, potencializam a atividade empreendedora imbricada nas transações de recursos escassos (Granovetter, 1973, 1983; Ahuja, 2000; Ikenami, 2016).

Entende-se a formação de redes como uma estratégia organizacional que promove as iniciativas empreendedoras e lhes concede vantagens competitivas, por favorecer a produtividade e a escala de inovação e, consequentemente, o incremento do ambiente de negócios, cujo ciclo se retroalimenta, incentivando a abertura de novos negócios. As redes são definidas como combinações de convivência e reciprocidade marcadas pela confiança entre seus integrantes. Esse atributo conduz ao acesso e compartilhamento de informações e conhecimentos, à cooperação, ao respeito aos acordos estabelecidos e à utilização de mentorias para a solução de problemas e a tomada de decisão em conjunto, elementos imprescindíveis ao processo de consolidação do empreendedorismo (Wellman, Haase, Witte \& Hampton, 2001; Pinto \& Junqueira, 2009).

A concepção de rede social traz uma alternativa ao modelo clássico de estrutura piramidal, haja vista que as interconexões nela estabelecidas são marcadas pela informalidade e permitem a seus participantes um fluxo de comunicação horizontalizado, sem hierarquias. Nesse formato, quando há simetria nas relações qualquer integrante tem igual capacidade de exercer o papel de liderança, facilitando, o atingimento dos objetivos organizacionais (Withaker, 1993; Grandori \& Soda, 1995).

Castells (1999) define redes como sistemas abertos que se alteram conforme o acréscimo ou a retirada de integrantes para o alcance de algum objetivo. Em sua concepção, as redes podem ser entendidas como o conjunto de nós (agentes/atores) que se conectam. Para o autor, desde que haja compartilhamento de informações entre seus membros, as redes são capazes de se expandir de forma ilimitada, agregando novos nós, sendo que este modelo, põe em xeque os conceitos convencionais de individualismo e de relações de poder, implicando a inserção social, política e econômica de seus integrantes, a partir de novos pressupostos.

Gulati, Nohria e Zaheer (2000) ressaltam a colaboração empresarial como instrumento que apoia a obtenção de informação, fortalece a confiança, reforça o aconselhamento e as parcerias e amplia a capacitação, cujos atributos propiciam a expansão das competências, ganhos de escala, compartilhamento de riscos e expansão de mercado para seus atores.

No entendimento de Capra (2002), redes são emaranhados comunicativos que utilizam expressões simbólicas, cult urais e de poder. São instrumentos de políticas públicas que promovem o combate às desigualdades por meio da colaboração.

$\mathrm{O}$ estudo das redes no âmbito empresarial pode facilitar a definição de posicionamentos, canais de relacionamentos e oportunidades mercadológicas, além de desvendar os interesses que provocam o seu dinamismo. Isso porque as redes atuam como apoio à melhoria do fluxo de informações, agregação de competências e promoção da inovação, ao propiciarem o encadeamento lógico dos relacionamentos entre seus integrantes, possibilitando a formatação da estrutura social (Sacomano NETO, 2003; Balestrin \& Vargas, 2004; Balestrin, 2005; Tomaél \& Marteleto, 2006).

Paula e Silva (2006) admitem que, diante das modernas técnicas de produção, as redes sociais funcionam como aporte instrumental e sociológico em prol das estratégias organizacionais, conceituando-as como um compilado de conexões que se relacionam para organizar as atividades produtivas com base na colaboração e no compartilhamento. 
Em suma, as redes se caracterizam como instrumento eficaz de ordenamento social, na medida em que, a partir dos atributos de colaboração e compartilhamento, propiciam lucratividade às empresas integrantes, gerando desenvolvimento social (Jesus \& Machado, 2011, Morinishi \& Guerrini, 2011; Silva, 2012).

Sob o ponto de vista processual, ocorre um encadeamento, simbiose e interconexão entre os termos ecossistemas e redes já que buscam a concretização de objetivos comuns, potencialização de esforços por meio de integrações e interações entre si (Moore, 1996).

Ademais, o ferramental propiciado pelos ecossistemas e redes apoiam a criação de ambiência favorável ao desenvolimento de habilidades, de modo que os atores envolvidos ampliem sua capacidade de orquestrar, articular, mobilizar e aglutinar recursos, competências e qualificações disponíveis tanto dentro, quanto fora dos seus limites de atuação, com vistas à geração de valor, a partir de atitudes colaborativas, interdependentes e interativas (Teece, 2009).

Nesse sentido, quanto mais favorável e denso for o ambiente externo no qual o ecossistema estiver inserido, mais recursos esse dispenderá para a inserção, consolidação, potencialização e difusão de práticas criativas e inovadoras (Neck, Meyer, Cohen, \& Corbett, 2004; Powers \& Mcdougall, 2005; Fetters, Greene, Rice, \& Butler, 2010).

Vale ressaltar, conforme Kenney e Patton (2006), que vários elementos devem ser considerados no processo de consolidação dos ecossistemas ancorados em redes de relacionamentos tais como os de natureza cultural, política, social e econômica.

Assim, as redes se apresentam com o propósito de atendimento às oportunidades empreendedoras e de publicização dos objetivos de seus integrantes, visando o alcance de ações mercadológicas bem-sucedidas, além de propiciar, pela via da colaboração, a expansão e inovação empresarial. As operações em rede resultam em compartilhamento de informações, tecnologias e conhecimentos permitindo aos atores integrantes o planejamento, o desenvolvimento, a aplicação e avaliação de suas iniciativas para o alcance de intenções comuns (Gasparetto, 2008; Borgatti \& Halgin, 2011; Ikenami \& Garnica, 2016).

\section{$3 \quad$ Metodologia}

A intenção da pesquisa foi descrever e analisar a forma como se estrutura a rede San Pedro Valley, a partir das medidas dimensionais de grau de centralidade de seus atores, e seus índices de centralização e densidade.

Desse modo, para a realização desse trabalho, buscou-se aplicar um questionário que identificasse as organizações da rede mais lembradas quando se trata dos atributos: efetuar contatos, buscar informação, manter uma relação de confiança, obter aconselhamento e capacitação (mentoring e consultoria), contribuir para o processo decisório e construir acordos de cooperação/parceria e/ou aliança.

A população pesquisada compreendeu as empresas integrantes da comunidade San Pedro Valley, identificadas a partir do site institucional, o qual possuía 315 organizações cadastradas e distribuídas em: duas incubadoras, um espaço de coworking, oito aceleradoras, 37 agências digitais; um Hackerspace, cinco investidores e 252 startups (San Pedro Valley, 2017).

No decorrer do processo de pesquisa, foram identificadas cinco empresas falidas e 19 gestores disseram que não fazem parte da comunidade, seja porque não sabiam que tinham 
cadastro no site, seja porque já fizeram parte no passado, mas que hoje já não fazem mais. Nesse sentido, o universo passou a contar com 291 organizações, sendo que deste total 145 responderam ao questionário, por meio de telefonemas (130) ou pelo questionário online (15). Acrescenta-se que durante a entrevista 10 se recusaram a responder, 18 não puderam ser contatadas, em razão da desatualização de cadastro e 118 solicitaram um questionário online, mas não responderam.

Dessa forma, conforme cálculo de amostragem aleatória simples finita, retirado da fórmula fornecida por Gil (1999), realizou-se entrevistas em uma amostra de 145 casos, que significa que os dados obtidos possuem um nível de confiança de $95 \%$ e erro amostral de $5,77 \%$.

A análise quantitativa compreendeu três dimensões, a saber, centralização e densidade da rede (Marwell, Oliver \& Prahl, 1988) e centralidade dos atores na rede.

\section{$4 \quad$ Resultados e análise da estrutura das redes da San Pedro Valley}

Um dos achados dessa pesquisa é a incidência de citações de empresas que não fazem parte da rede formal (aquela apresentada pelo site oficial da San Pedro Valley). No total, registrou-se relações sociais com 121 empresas externas à rede formal, que doravante, para fins de padronização, serão denominadas de "externas". Diante dessa dimensão, para dois desses atributos (contatos e parcerias), os quais se convencionou considerá-los como undirected", os cálculos de suas respectivas redes passarem a fazer uma distinção entre a rede formal e a rede informal (que considera a rede social formada por ambas, organizações cadastradas e não cadastradas, que mantêm relações sociais entre si). Esse fato apresenta indícios da expansão da rede para além de seus limites formais.

Para os demais cinco atributos - informação, confiança, aconselhamento, capacitação (Mentoring e consultoria) e identificação dos atores fundamentais para o desenvolvimento da rede -, convencionou-se que as relações, por serem diretas (em que a relação de x com y não necessariamente reflete a relação de y com X), foram obtidas estatísticas apenas para a rede que contempla as relações formais, ou seja, entre as organizações integrantes da rede San Pedro Valley. Os códigos apresentados nos diagramas/grafos de cada rede podem ser interpretados da seguinte maneira: $\mathrm{AC}=$ Aceleradoras; $\mathrm{AD}=$ Agências Digitais; $\mathrm{CO}=$ Coworking; $\mathrm{HA}=$ Hackerspace $; \mathrm{INC}=$ Incubadoras; INV = Investidores; $\mathrm{ST}=$ Startups; EXT = Externas (organizações não cadastradas no site da San Pedro Valley)

\subsection{Rede informal de contatos dos membros da San Pedro Valley}

A rede de contatos é caracterizada por relações não direcionadas (undirected), o que significa que os laços não têm direção definida, ou seja, ao invés de setas, tem-se linhas não hierárquicas. Nesse caso, se a empresa $X$ tem contato com a empresa $Y$, necessariamente esta tem contato com aquela. A figura 1 mostra o diagrama/grafo da rede informal de contatos ("Cite as organizações da rede San Pedro Valley com as quais sua empresa mantém contato (efetua ligações, troca e-mails, participa de reuniões, encontra em eventos”). 


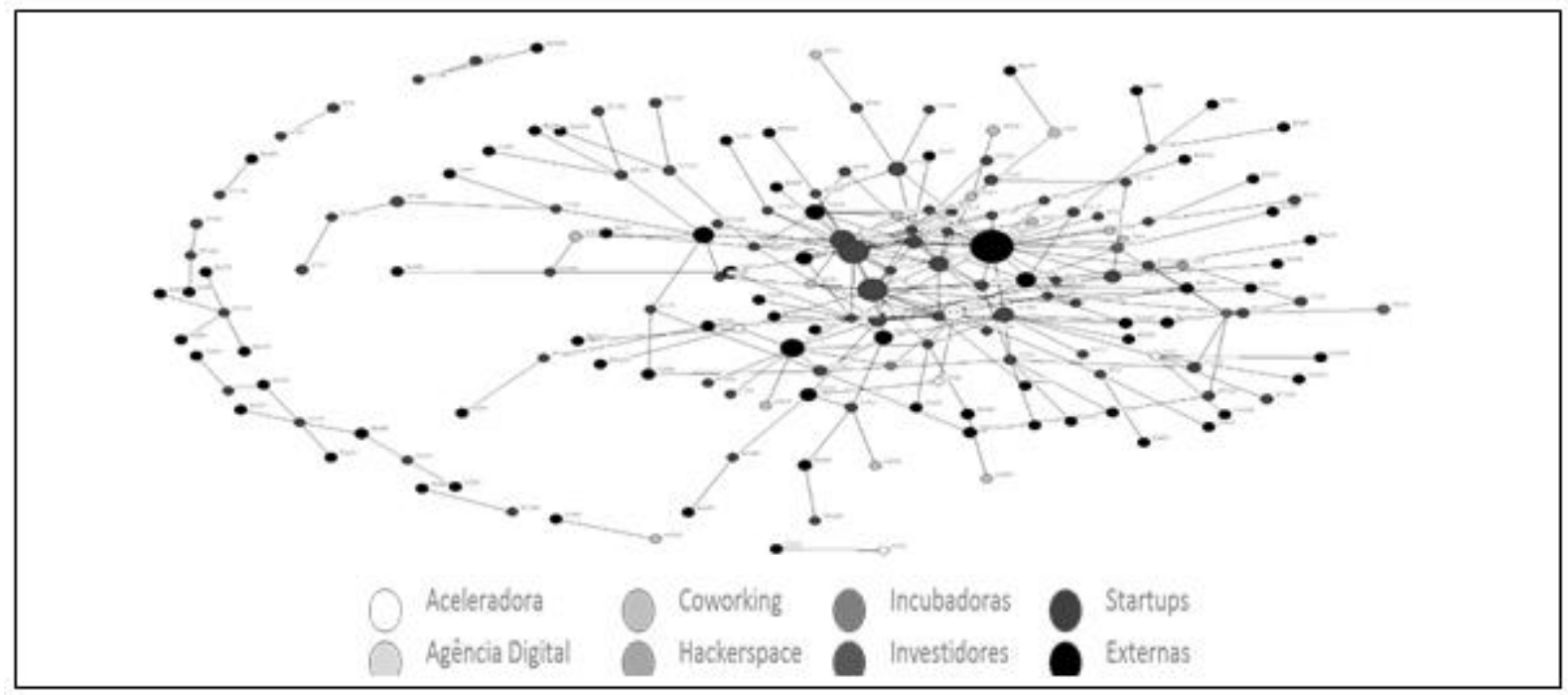

Figura 1 - Rede informal de contatos

Fonte: Dados da pesquisa

Três pontos se destacam ao observar na figura 1. Primeiro, a constatação de uma quantidade considerável de citações de organizações externas à San Pedro Valley - 71 no total. Segundo a verificação de que se trata de uma rede nucleada, pois apresenta um núcleo saliente de atores de referência (atores centrais), observado pelos nós maiores. O curioso é que a empresa de maior grau de centralidade da San Pedro Valley (Ext17) é externa à rede. Terceiro, ao observar os pontos concentrados no lado esquerdo, é perceptível o conjunto de empresas periféricas que não estão conectadas com o núcleo central da rede. Elas fazem pequenas conexões entre si (díades ou tríades).

A partir do grau de centralidade dos atores, considerando os laços tanto de saída como de entrada, identificou-se que das 10 das empresas mais centrais (tabela 1), duas são externas à rede, sete são startups e uma aceleradora. Do total de empresas entrevistadas, registraram-se 83 instituições com apenas um laço e 92 sem vínculo algum com a rede.

Considerando que os atores centrais são responsáveis pelo dinamismo da rede e assumem papel privilegiado no acesso e compartilhamento de recursos provenientes da rede (Marteleto, 2001; 2006; Scott, 2007), parece conveniente inferir que neste estudo de caso o dinamismo da rede de contatos está, em certa medida, associado às startups e a empresas externas.

O índice de centralização da rede informal de contatos é de 7,7\%, o que demonstra a difusão dos laços entre os nós. Isso pode ser influência da grande quantidade de atores da rede San Pedro Valley sem nenhum tipo de contato com os demais membros (92) e do fato de os atores interagirem com poucas empresas sem passar pelo núcleo central.

É importante ressaltar que para os 92 casos com nenhum contato (0), adotou-se como critério a sua exclusão da figura, de modo a não deturpar a visualização das interações verificadas. Portanto, sobre o índice de centralização da rede, há de se ter cautela em sua interpretação: apesar de se perceber um núcleo bem definido, ao olhar o conjunto da rede, ela tem aspectos que a caracteriza como uma rede difusa/descentralizada. 
O grau de densidade, que mede o quociente entre o número de relações existentes e o número de relações possíveis, foi de $0,5 \%$, indicando baixa conectividade e pouca aderência entre seus membros, resultando em fracas conexões. Significa dizer que é baixa a probabilidade de seus integrantes tomarem decisões conjuntamente (Granovetter, 1983; Coleman, 1988; Ahuja, 2000).

Tabela 1

Grau de centralidade dos atores da rede informal de contatos

\begin{tabular}{cccc}
\hline $\mathbf{n}$ & Código da empresa & Grau de centralidade & $\begin{array}{c}\text { Grau de centralidade } \\
\text { normalizado }\end{array}$ \\
\hline $\mathbf{1}$ & Ext17 & 22,000 & 0,083 \\
$\mathbf{2}$ & ST139 & 17,000 & 0,064 \\
$\mathbf{3}$ & ST202 & 16,000 & 0,061 \\
$\mathbf{4}$ & ST223 & 14,000 & 0,053 \\
$\mathbf{5}$ & ST89 & 12,000 & 0,045 \\
$\mathbf{6}$ & ST211 & 12,000 & 0,045 \\
$\mathbf{7}$ & ST131 & 11,000 & 0,042 \\
$\mathbf{8}$ & ST243 & 11,000 & 0,042 \\
$\mathbf{9}$ & AC7 & 9,000 & 0,034 \\
$\mathbf{1 0}$ & Ext15 & 9,000 & 0,034 \\
\hline
\end{tabular}

Fonte: Dados da pesquisa

\subsection{Rede formal de contatos dos membros da San Pedro Valley}

Traçou-se também a rede formal baseado no questionamento sobre organizações da rede San Pedro Valley com as quais uma empresa em particular mantém contato.

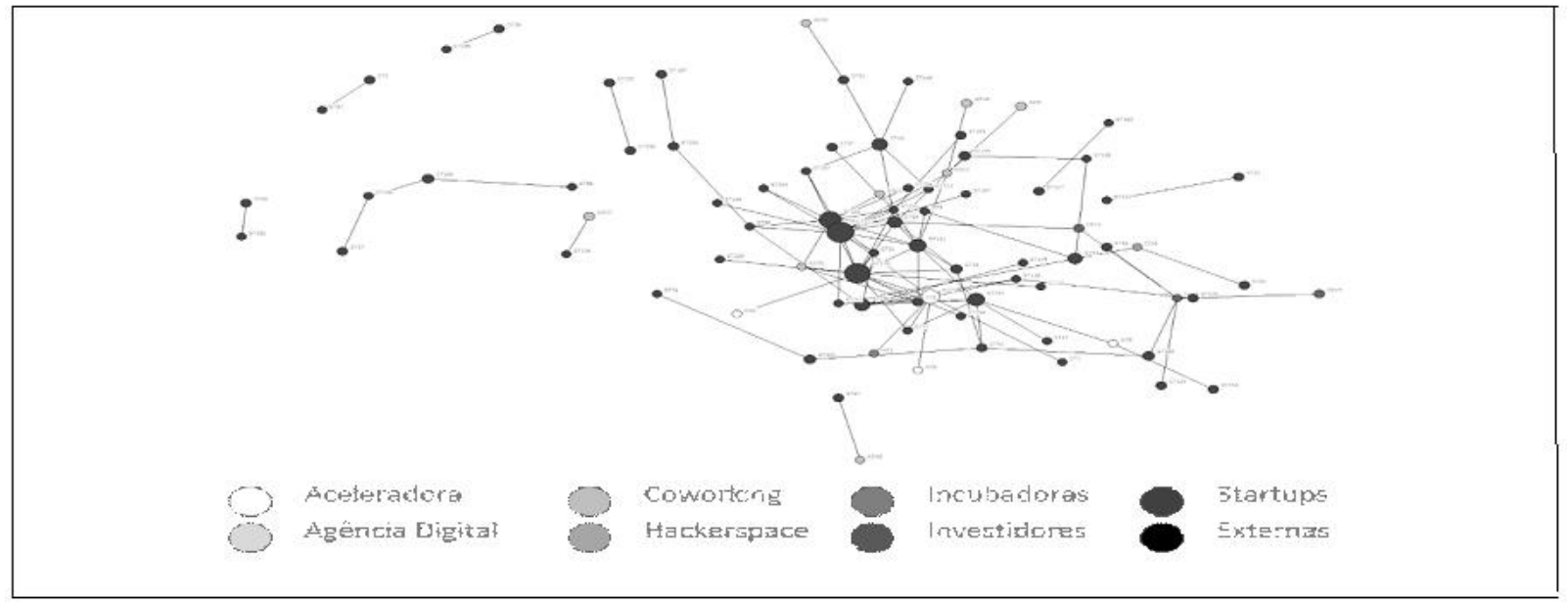

Figura 2 - Rede formal de contatos

Fonte: Dados da pesquisa

Ao se fazer um paralelo entre as duas redes de contatos, percebe-se que ocorre um decréscimo do grau de conexões na rede formal relativamente à rede informal, já que o número de nós cai de 265 para 82 e o número de laços passa de 384 para 110, apesar do grau de centralização e a densidade permanecerem em patamares próximos (passa de 7,7\% para $7,2 \%$ e de $0,5 \%$ para $0,3 \%$, respectivamente. Pode-se inferir que os atores da rede formal 
executam menos contatos entre si, o que reforça a importância dos atores externos na estruturação desse atributo.

\subsection{Rede informal de relação de parcerias, cooperação e alianças da San Pedro Valley}

Assim como na rede de contatos, convencionou-se que as relações do atributo Parceria/cooperação e alianças também são bidirecionais (undirected). Ou seja, se a empresa $\mathrm{X}$ mantem relações de parceria com a empresa $\mathrm{Y}$, necessariamente ela mantém relações de parceria com aquela. $\mathrm{O}$ grafo da rede não apresenta setas de direcionamento das relações entre os nós e sim uma linha não hierárquica que demonstra a conexão.

Nessa rede, do mesmo modo que na de contatos, também se observam três pontos que merecem menção. Primeiro, a constatação de uma quantidade considerável de indicações de organizações externas à San Pedro Valley. Sobre isso, identifica-se a existência de 30 organizações externas, responsáveis por 41 laços do total de 134. Segundo a constatação, mais uma vez, de nucleação da rede, em que há a existência de atores centrais identificados pelos maiores nós, sendo que, de novo, o maior grau de centralidade está atrelado a uma organização externa à comunidade (Ext17). Terceiro, diz respeito ao grande número de conexões dispersas e pulverizadas ao longo da rede desconectadas do núcleo central. Seguindo a mesma linha de raciocínio da rede de contatos, parece oportuno apontar a existência de pequenos núcleos periféricos relativamente ao núcleo central. ("Com quais organização da rede sua empresa desenvolve ou está desenvolvendo projetos de parceria, cooperação e/ ou alianças?”).

Com efeito, ao considerar os laços tanto de saída como de entrada, a tabela. 2 elenca os 10 atores que apresentaram maior grau de centralidade em termos de manutenção de relações de parcerias por ordem decrescente do grau de centralidade.

Tabela 2

Grau de centralidade dos atores da rede informal de parcerias

\begin{tabular}{cccc}
\hline $\mathbf{n}$ & Código da empresa & Grau de centralidade & Grau de centralidade normalizado \\
\hline $\mathbf{1}$ & Ext17 & 10.000 & 0.054 \\
$\mathbf{2}$ & ST202 & 9.000 & 0.048 \\
$\mathbf{3}$ & ST221 & 9.000 & 0.048 \\
$\mathbf{4}$ & ST118 & 7.000 & 0.038 \\
$\mathbf{5}$ & ST113 & 5.000 & 0.027 \\
$\mathbf{6}$ & ST212 & 5.000 & 0.027 \\
$\mathbf{7}$ & ST243 & 5.000 & 0.027 \\
$\mathbf{8}$ & AD21 & 4.000 & 0.022 \\
$\mathbf{9}$ & ST9 & 4.000 & 0.022 \\
$\mathbf{1 0}$ & ST89 & 4.000 & 0.022 \\
\hline
\end{tabular}

Fonte: Dados da pesquisa.

No top 10 das empresas mais centrais encontram-se uma empresa externa, oito startups, e uma agência digital. Ao considerar toda a amostra pesquisada, registraram-se 61 instituições com apenas um laço e 82 afirmaram que não estruturaram iniciativas em parceria/cooperação com a rede. É possível afirmar que a rede de parceiros é constituída de um núcleo central e diversas conexões periféricas, as quais circundam o núcleo central. E, ainda, há um conjunto considerável de empresas situadas na periferia da rede, desconectadas do núcleo. Contudo, intercambiam conexões entre si. 
A centralização da rede informal de parceria foi de 0,0489 . Ou seja, a capacidade do núcleo de estabelecer parcerias é de apenas $4,89 \%$. O baixo percentual pode ser consequência do fato de que 82 organizações entrevistadas afirmarem não possuir nenhuma relação de parceria ou aliança e de que 61 possuíam apenas um parceiro.

Com respaldo no fenômeno acima descrito, o grau de densidade da rede informal de parceria e alianças foi de $0,004(0,4 \%)$, indicador que sinaliza uma quantidade ínfima de conexões, denotando baixo grau de aderência e coesão entre seus integrantes na manutenção de relações de parcerias.

\subsection{Rede formal de relação de parcerias, cooperação e alianças da San Pedro Valley}

Com o intuito de fornecer uma visão do que seria a rede San Pedro Valley ao se considerar apenas seus membros, apresenta-se a rede formal desse atributo, conforme figura. 3 ("Com quais organização da rede sua empresa desenvolve ou está desenvolvendo projetos de parceria, cooperação e/ ou alianças?”)

Se comparada à informal, a rede formal apresenta um decréscimo de mais de $50 \%$ de números de nós, confirmando a intensidade da participação de atores externos no processo de consolidação de parcerias. O índice de centralização de $4,11 \%$ implica a dispersão dos laços estabelecidos na rede. As conexões são ainda mais irrelevantes se comparadas à rede informal, cujo grau de densidade é de $0,2 \%$. Isso pode implicar na inexistência de concentração deste atributo em integrantes específicos.

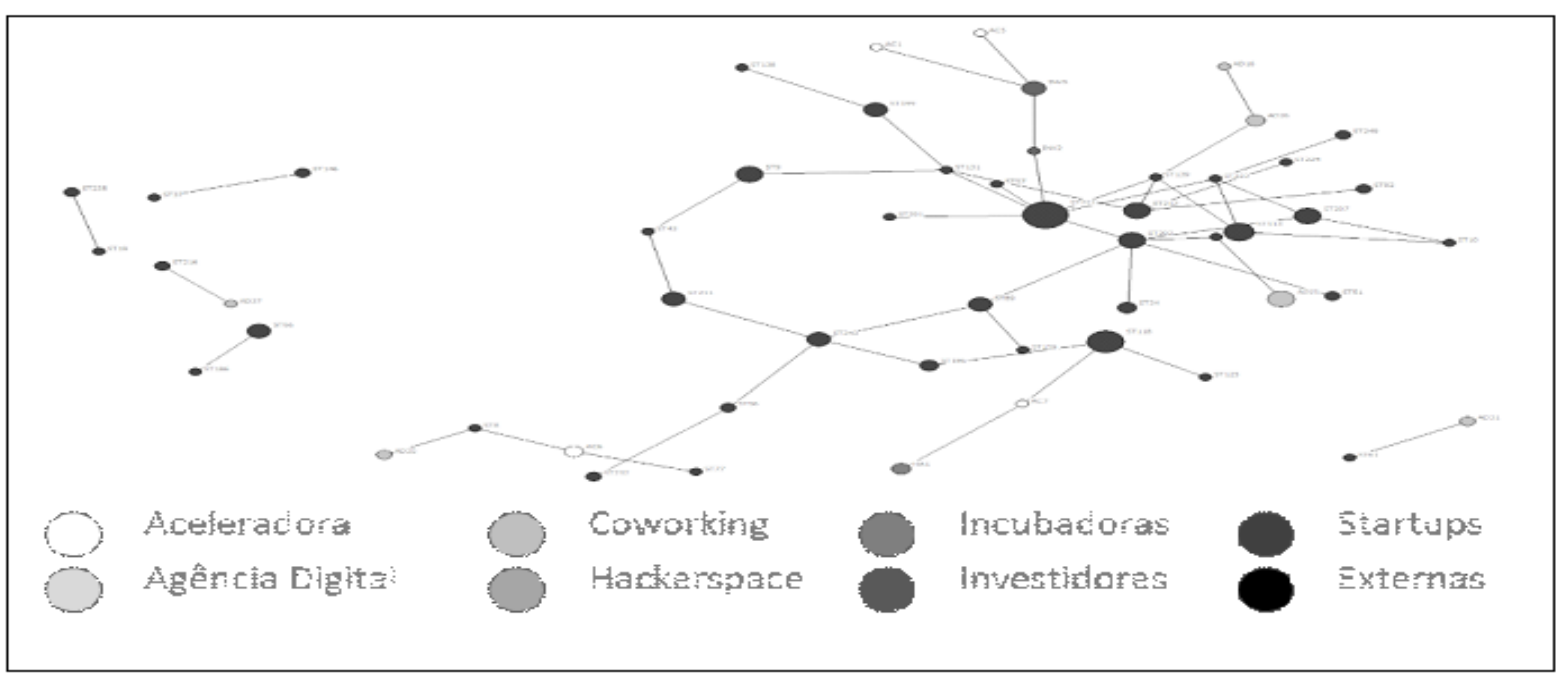

Figura 3 - Rede formal de Relação de parcerias

Fonte: Dados da pesquisa

\subsection{Rede informal de busca por informações dos membros da San Pedro Valley}

Esta rede apresenta diferenciações em relação às duas anteriores, por perseguir o seguinte preceito lógico: se a empresa $\mathrm{X}$ busca informação em $\mathrm{Y}$, pode não ser verdadeiro a reciprocidade de que esta busque informação naquela. Dessa forma, trata-se de uma rede de relações direcionadas (directed), que é simbolizada na figura $4 \mathrm{com}$ os laços identificando a direção (seta) da relação. ("O processo de gestão exige a busca constante em informações. 
Nesse sentido, cite as organizações da rede as quais você recorre para obter informações uteis para seu negócio")

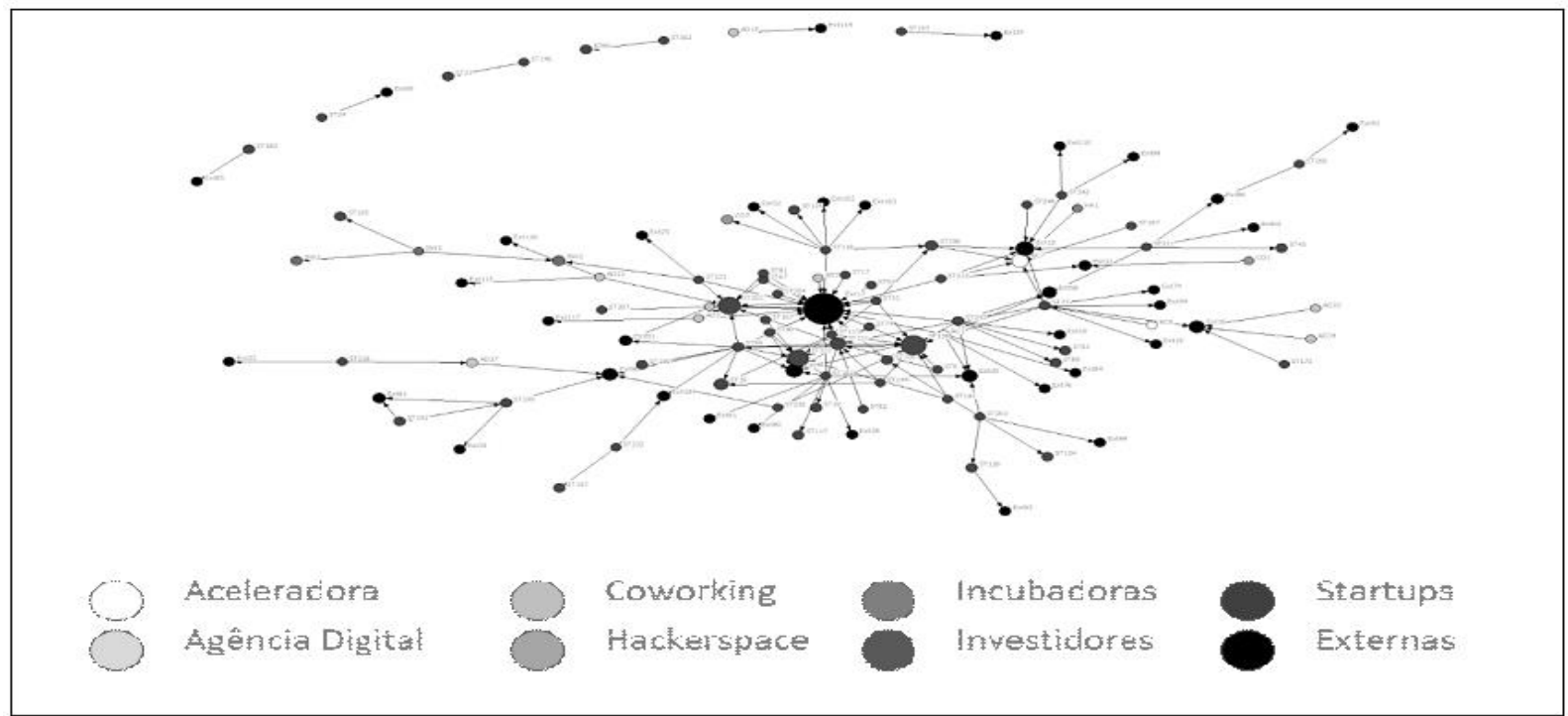

Figura 4 - Rede informal de busca por informações

Fonte: Dados da pesquisa

A visualização da rede informal permite identificar que se trata de uma rede de formato mais horizontalizado, o que não significa que há horizontalização na busca por informações. O desenho deixa claro o núcleo de referência da rede no centro do grafo (cuja empresa é externa à rede) e uma quantidade significativa de nós orbitando à sua volta. Alguns dos pequenos acabam assumindo o importante papel de conectar os nós mais distantes, que se situam mais à direita e mais à esquerda do núcleo. Ainda, observam-se algumas díades na parte superior desconectadas do fluxo de informação da rede. Por fim, como já identificado anteriormente, ressalta-se o papel importante para a estruturação da rede desempenhado por organizações externas.

\subsection{Rede formal de busca por informações dos membros da San Pedro Valley}

Ao se considerar apenas a rede formal da San Pedro Valley sobre busca por informação ("O processo de gestão exige a busca constante em informações. Nesse sentido, cite as organizações da rede as quais você recorre para obter informações uteis para seu negócio").

Das 145 entrevistas realizadas, identificaram-se apenas 59 nós entre as organizações internas em que há algum vínculo de busca e fornecimento de informações. Existem 66 laços que conectam essas empresas neste atributo. O baixo número de laços entre os nós se reflete no grau de densidade da rede, que é de $0,3 \%$. Há atores que compõem o núcleo e que são de certa forma referência para a busca por informações (simbolizados pelos círculos maiores), todavia, o grau de centralização de entrada é baixo sendo apenas de $6,83 \%$. Vale notar que as startups são as organizações que apresentam os maiores graus de centralidade. 


\subsection{Rede informal de relações de confiança da San Pedro Valley}

Os gestores foram questionados também sobre as organizações da rede com as quais pela conduta ética e pela respeitabilidade observada no mercado eles mantêm uma relação de confiança (Figura 5).

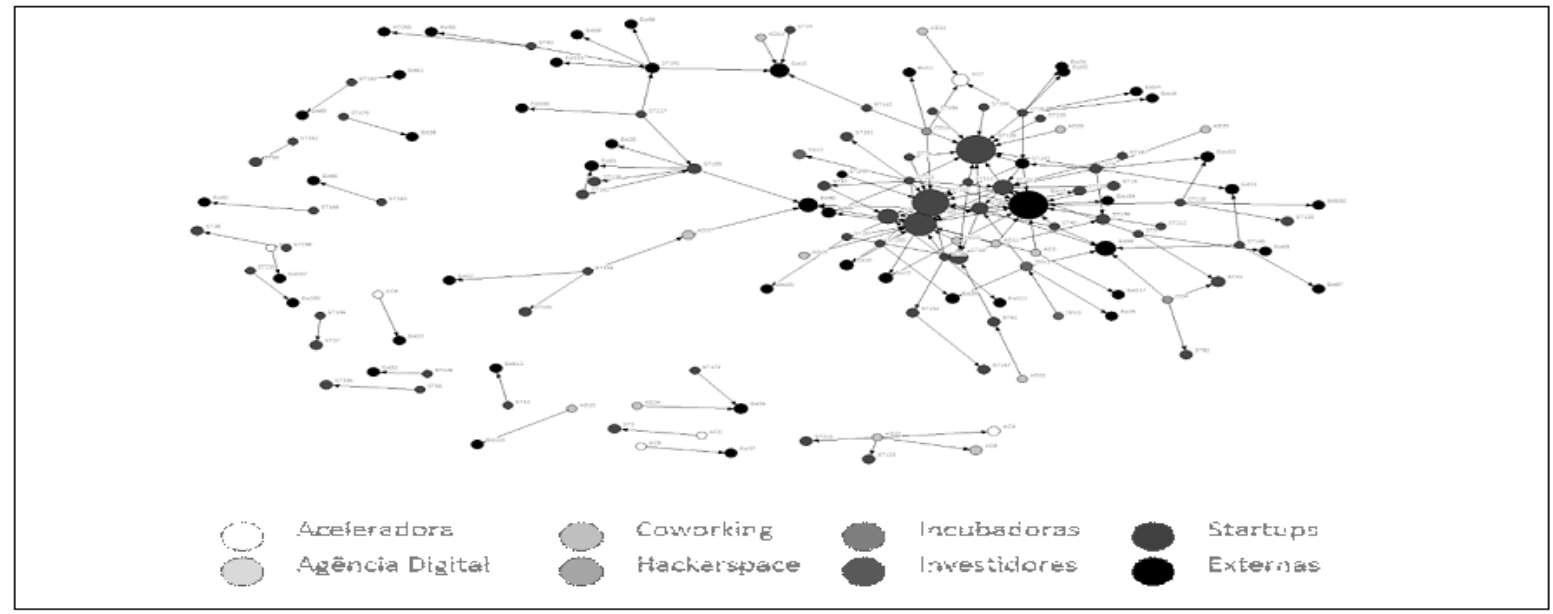

Figura5 - Rede informal de relação de confiança

Fonte: Dados da pesquisa

Diferentemente das demais redes analisadas até este ponto, a rede de confiança traz uma representação diferenciada. A centralidade dos atores que formam o núcleo de referência da rede é facilmente observada, sendo que uma grande quantidade de nós converge para esse núcleo central de forma mais evidente. Estes nós tornam-se sobressalentes devido ao tamanho dos círculos e estão expostos no componente à esquerda. Dessa forma, vai se consolidando a percepção de que a San Pedro possui empresas que emanam confiança para as demais e contribuem para a estruturação do ecossistema. Em contrapartida, é visível no diagrama a existência de um conjunto significativo de organizações que fazem ligações entre si e se encontram na periferia da rede.

\subsection{Rede formal de relações de confiança da San Pedro Valley}

Esta rede demonstra que a confiança é um importante atributo de estruturação da rede. A partir do núcleo concentrado à direita, percebe-se que há poucas empresas "polos" e várias em sua periferia. Aqui, é possível refletir sobre a hipótese de que a boa reputação no mercado e a referência desempenhada pelas empresas centrais acabam disseminando no ecossistema a percepção de que a rede como um todo também é confiável. De outro lado, registram-se pequenos nichos de empresas que acabam desenvolvendo relações de confiança entre si, sem necessariamente passar pelas empresas centrais. ("Cite as organizações da rede com as quais pela conduta ética e pela respeitabilidade observada no mercado, você mantém uma relação de confiança.")

Internamente à San Pedro Valley, foram identificados 75 nós, que estabelecem 91 laços de confiança. Como o núcleo das empresas de referência da rede fica mais evidente, o grau de centralização de entrada (7,92\%) é superior ao das redes analisadas anteriormente. Já a densidade da rede, que também sofre o efeito dos atores com ausência ou baixa conexão, 
permanece baixa, 0,4\%. Ou seja, as conexões existentes possuem baixa aderência, considerando todas as possibilidades de conexões.

Há baixa incidência de atores ligados diretamente aos atores centrais se for considerado todo o universo de organizações da comunidade.

\subsection{Rede informal de busca por aconselhamento da San Pedro Valley}

A rede de aconselhamento deste estudo de caso é uma das que agregam menor número de organizações. Foi perguntado aos entrevistados onde eles buscam não só informações úteis, mas também aconselhamentos.

Ao analisar a figura 6, identificam-se duas organizações de referência para o aconselhamento. Uma é interna e outra é externa. Nesse aspecto, mais uma vez, essa empresa externa desempenha o papel de estruturar a rede, pois há uma série de empresas periféricas que se conectam ao componente principal por meio dela. Diante da amplitude da rede, também é perceptível que buscar por aconselhamento não é um hábito enraizado na comunidade, senão uma prática de apenas algumas empresas.

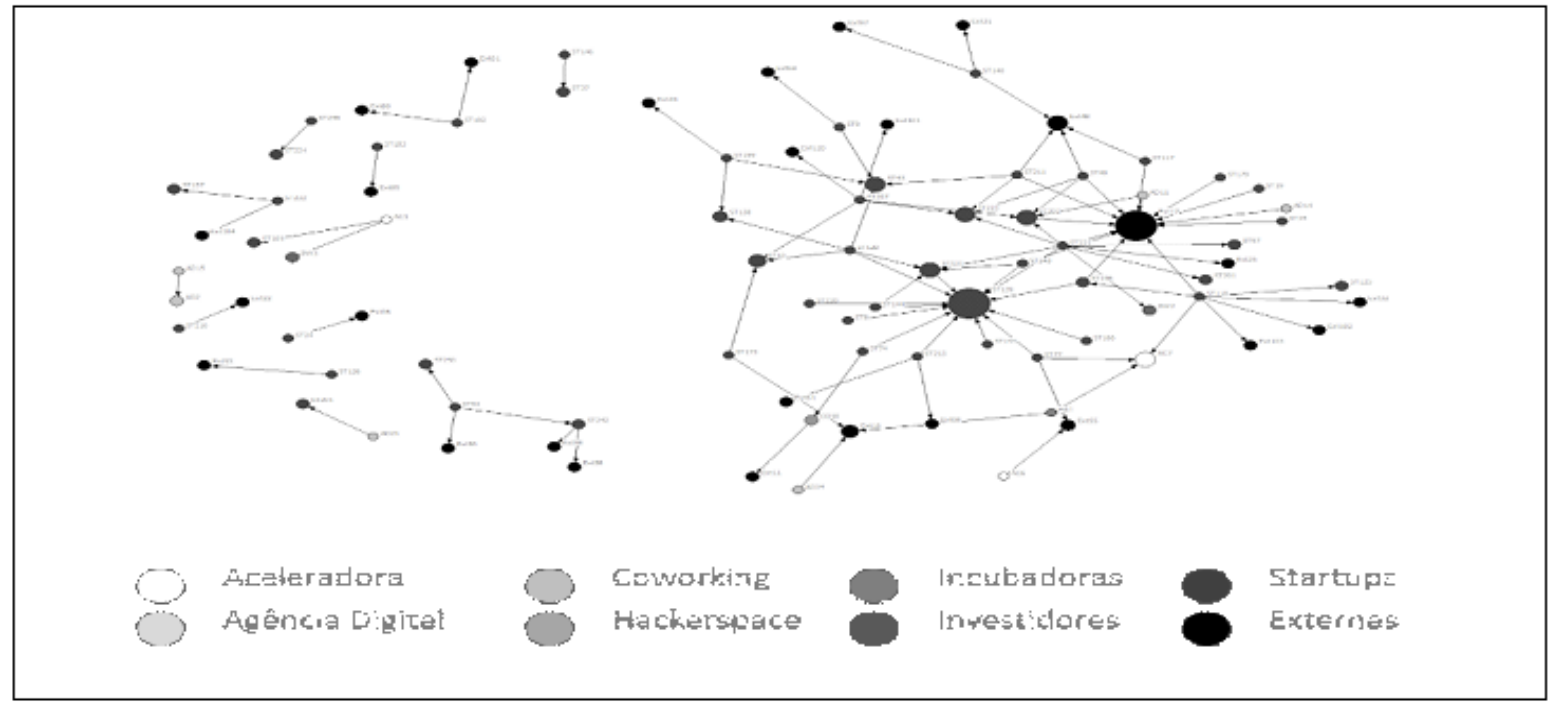

Figura 6 - Rede informal de busca por aconselhamento

Fonte: Dados da pesquisa

\subsection{Rede formal de busca por aconselhamento da San Pedro Valley}

Considerando que esse atributo está representado por poucos nós entre seus integrantes, optou-se pela não apresentação de visualização gráfica da rede formal, cujo índice de densidade é de $0,2 \%$. A centralização dessa rede formal apresenta um grau de entrada da ordem de $8,22 \%$, sendo ambas as dimensões relativamente baixas

\subsection{Rede informal de busca por capacitação (mentoring, assessoria e consultoria) da San Pedro Valley}

Percebe-se na rede San Pedro Valley um processo informal de capacitação entre seus membros. Com efeito, observou-se, novamente, a presença mais incisiva de empresas 
externas que assumem um papel central. ("Você busca capacitação (mentoring, assessoria e consultoria) com quais organizações da rede?")

\subsection{Rede formal de busca por capacitação (mentoring, assessoria e consultoria) da San Pedro Valley}

Do mesmo modo que na rede formal de aconselhamento, convencionou-se não demonstrar graficamente o diagrama da rede formal já que sua centralização é a menor dos atributos analisados, sendo de 4,39\%. A medida de densidade confirma tal percepção, tratando-se de uma das redes de densidade mais baixa, $0,2 \%$.

\section{4,13 Rede informal de percepção dos atores fundamentais para o desenvolvimento da San Pedro Valley}

Este atributo, de algum modo, relata a percepção de importância de atores internos à rede como organizações de referência para a estruturação e a consolidação da rede, apesar de se perceber também a representatividade de atores externos. Isso pode ser analisado a partir da figura 7 ("Cite as empresas da comunidade que você considera fundamentais para o desenvolvimento da rede.”),

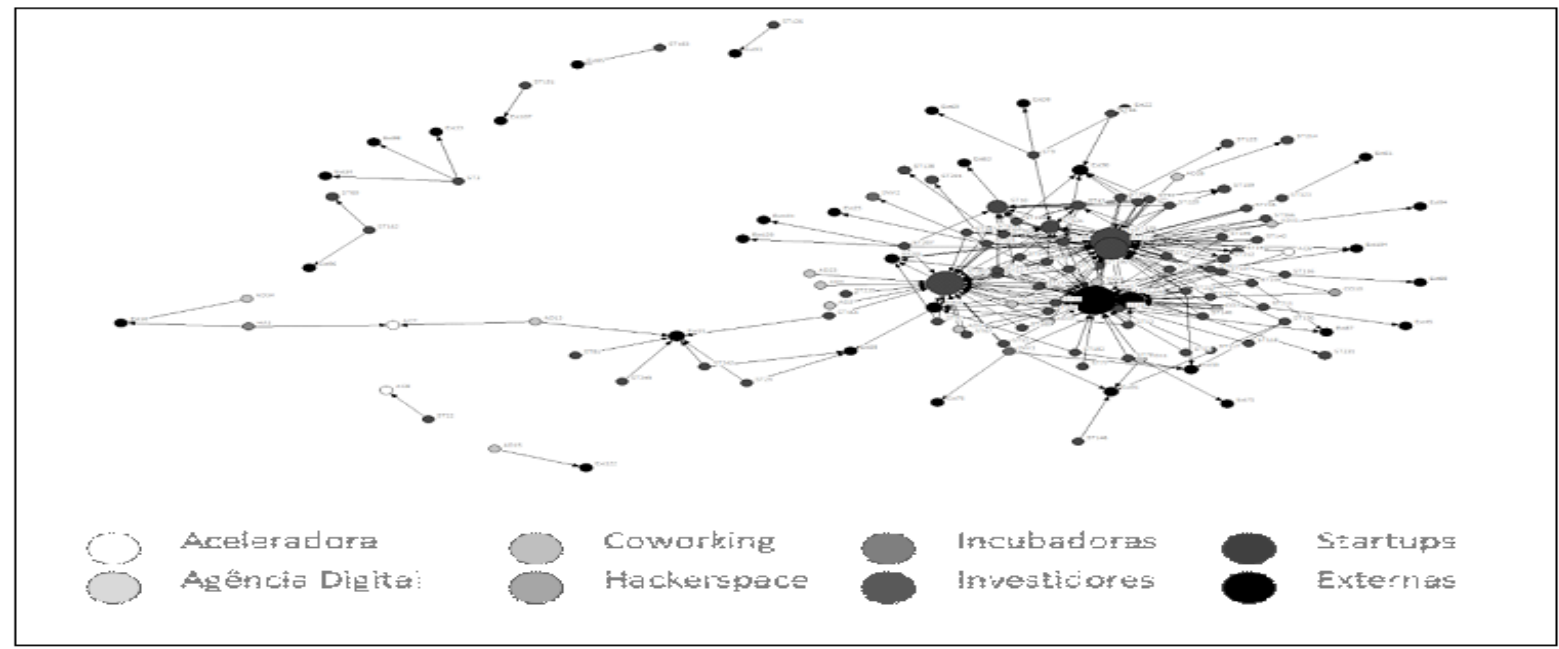

Figura 7- Rede informal de percepção dos atores fundamentais para o desenvolvimento da rede Fonte: Dados da pesquisa

Percebe-se a distinção do seu formato em relação aos demais atributos analisados. Há maior número de laços que convergem para as empresas do núcleo, o que reflete a maior densidade da rede. Outro fator passível de análise diz respeito à ausência das incubadoras na rede e à pouca inserção das agências digitais.

\subsection{Rede formal de percepção dos atores fundamentais para o desenvolvimento da San Pedro Valley}

Os atores internos à rede desempenham papel crucial ao desenvolvimento da rede, pois, ao se analisar o grafo da rede formal, tem-se uma clara noção da relevância de alguns 
atores nesse processo ("Liste as empresas da comunidade que você considera fundamentais para o desenvolvimento da rede").

A análise das estatísticas deixa evidente o quanto a percepção de importância dos atores é relevante para a rede. Esta é a rede que possui um grau de centralização de entrada relativamente expressivo em relação às demais $(25,68 \%)$ e a que apresentou a maior densidade, $0,6 \%$, o que indica que é relativamente menos difusa do que as demais analisadas.

Quando se analisa o grau de centralidade de entrada normalizado, observa-se que há três organizações que se destacam fortemente: as startups ST139, com grau de centralidade de entrada de 26,1\%; ST202, com 22,2\%; e ST223, com 19,6\%.

\section{$5 \quad$ Considerações Finais}

A rede San Pedro Valley tem em sua concepção a visão de promover a inovação e o empreendedorismo, com a finalidade de conectar tecnologias e parceiros. No entanto, identificou-se a uma lacuna entre a concepção e a prática, uma vez que a mesma apresenta índice relativamente baixo de densidade na grande maioria dos atributos investigados.

A análise de centralidade dos atores indica uma concentração expressiva das relações centradas em poucas organizações, sendo essas, em muitos casos, externas à rede propriamente dita. Esse fenômeno promoveu a premência de se estabelecer, no âmbito das análises efetuadas, a distinção entre rede formal, constituída apenas por organizações cadastradas no site da rede, e rede informal, composta por todas empresas citadas questionários aplicados.

De forma geral, a comunidade San Pedro Valley caracteriza-se por laços pouco expressivos entre seus atores, haja vista a densidade reduzida referente a relações de comunicação, confiança, mentoring, entre outras. Nesse sentido, seria de grande pertinência o aumento do número de relações entre os atores da rede de forma a contribuir para a sua proposição inicial de promover o empreendedorismo no ecossistema empreendedor do município de Belo Horizonte.

Neste contexto, destaca-se a necessidade de incrementar a participação das aceleradoras e de investidores como forma de assegurar a sustentabilidade das startups, além da integração de incubadoras ao ecossistema, uma vez que empresas desse tipo não foram citadas por gestores como participantes da rede de empreendedorismo.

Em suma, os resultados indicam uma rede relativamente ampla, mas com baixa densidade e com um número elevado de atores periféricos sem conexão com o núcleo central. Neste sentido, embora a San Pedro Valley tenha como visão promover a inovação e o empreendedorismo, o baixo índice de densidade conduz a uma lacuna entre a proposição e a prática, indicando concentração de relações, poder e influência entre poucas organizações, algumas destas não participantes da rede formal.

Uma das limitações do presente estudo refere-se à impossibilidade de contatar os atores externos à rede citados pelas empresas integrantes da rede formal, fato que acarretou na diagramação de duas redes distintas (formal e informal) para cada atributo investigado. A percepção dos gestores da rede poderia contribuir para o aprofundamento de questões importantes emergidas durante a investigação.

Por fim, sugere-se como possibilidade de estudos futuros o aprofundamento das questões surgidas durante a investigação, como por exemplo, a alta incidência de empresas 
externas (não castradas formalmente no site da comunidade) a receberem papel estratégico no processo de consolidação e desenvolvimento da comunidade San Pedro Valley, e o índice baixo de densidade associado a centralização substancial observados na rede.

\section{Referências}

Ahuja, G. (2000). Collaboration networks, structural holes, and innovation: a longitudinal study. Administrative Science Quarterly, 45(3), 425-455.

Balestrin, A., \& Vargas, L. M. (2004). A dimensão estratégica das redes horizontais de PMEs: teorizações e evidências. Revista de Administração Contemporânea - RAC, 8(n. spe.), 203-227.

Balestrin, A., \& Verschoore, J. R. (2008). Redes de cooperação empresarial: estratégias de gestão na nova economia. Porto Alegre: Bookman.

Borgatti, S. P., \& Halgin, D. S. (2011). On network theory. Organization Science, 22(5), 1168-1181.

Capra, F. (2002). As conexões ocultas: ciência para uma vida sustentável. São Paulo: Cultrix2002.

Castells, M. (1999). A era da informação: economia, sociedade e cultura - a sociedade em rede. São Paulo: Paz e Terra.

Coleman, J. S. (1988). Social Capital in the Creation of Human Capital. The American Journal of Sociology,94, Supplement: Organizations and Institutions: Sociological and Economic Approaches to the Analysis of Social Structure, 95-120.

Faccin, K., \& Brand, F.C. (2015). Inovação aberta e redes: enfoques, tendências e desafios. Revista de Administração IMED,5(1), 10-35.

Fetters, M. L., Greene, P. G. Rice, M. P., \& Butler, J. B. (2010). The development of university-based entrepreneurship ecosystems: global practices. Edward Elgar.

Grandori, A., \& Soda, G. (1995). Inter-firm networks: antecedents, mechanisms and forms. Organization Studies, 16(2), 183-214.

Granovetter, M. (1994). Getting a job: a study of contracts and careers. Chicago: The University of Chicago Press.

Granovetter, M. (1992). Problems of explanation in economic sociology. In: N. Nohria, N., \& R. Eccles (Orgs.). Networks and organizations: structure, form and action. Boston: Harvard Business School Press.

Granovetter, M. (1983). The strength of weak ties: A network theory reviSited. Sociological Theory, 1, 201-233.

Granovetter, M. (1973). The strength of weak ties. American Journal of Sociology, 78(6), $1360-1380$.

Gil, A. C. (1999). Métodos e técnicas de pesquisa social. São Paulo: Atlas.

Gulati, R., Nohria, N., \& Zaheer, A. (2000). Strategic networks. Strategic Management Journal, 21, 203-215.

Ikenami, R. K., Garnica, L. A., \& Ringer, N. J. (2016). Ecossistemas de inovação: abordagem analítica da perspectiva empresarial para formulação de estratégias de interação. Revista de Administração, Contabilidade e Economia da Fundace, 7(1), 162-174.

Isenberg, D. J. (2010). How to start an entrepreneurial revolution. Harvard Business Review, Boston, 88(6), 40-50. 
Jarillo, J. C. (1988); On strategic networks. Strategic Management Journal,9(1), 31-41.

Jesus, M. J. F., \& Machado, H. V. (2011). A importância das redes sociais ou networks para o empreendedorismo. Revista Eletrônica de Administração - REA, 8(1), 1-11.

Kenney, M., \& Patton, D. (2006). The Coevolution of Technologies and Institutions: Silicon Valley as the Iconic High-Technology Cluster. In: P. Braunerhjelm, P., \& M. Feldman, M. (org.). Cluster genesis - Technology-based industrial development. Oxford: Oxford University Press.

Marteleto, R. M. (2001). Análise de redes sociais: aplicação nos estudos de transferência da informação. Ci. Inf., 30(1), 71-81.

Marwell, G., Oliver, P., \& Prahl, R. (1988). Social networks and collective action: a theory of the critical mass. III. American Journal of sociology, 94(3), 502-534.

Morinishi, M. T., \& Guerrini, F. M. (2011). Formação de redes de cooperação para o desenvolvimento de e-marketplaces verticais. Produção, 21(2), 355-365.

Moore, J. F. (1996). The death of competition: leadership and strategy in the age of business ecosystems. Nova Iorque: Harper Business.

Neck, H. M., Meyer, G. D., Cohen, B., \& Corbett, S. C. (2004). An entrepreneurial system view of new venture creation. Journal of Small Business Management, 42(2), 190-208.

Paula, A. P. P., \& Silva, R. S. (2006). Redes sociais e organizacionais. In: J. M. Boaventura (Org.). Redes de negócios: tópicos em estratégia. São Paulo: Saint Paul.

Pinto, A. M. G., \& Junqueira, L. A. P. (2009). Relações de poder em uma rede do terceiro setor: estudo de caso. Revista de Administração de Pública - RAP, 43(5), 1091-1116.

Powers, J. B., \& Mcdougall, P. P. (2005). Policy orientation effects on performance with licensing to start-ups and small companies. Research Policy, 34(7), 1028-1042.

Sacomano, M. Neto. (2003). Análise das redes: estrutura e relações. Anais do Encontro Nacional De Engenharia De Produção - ENEGEP. Rio de Janeiro, RJ, Brasil, 23.

Scott, J. (2007). Social network analysis: a handbook. London: SAGE.

Silva, S. R. (2012) Relacionamentos interorganizacionais em rede de cooperação: um estudo no setor farmacêutico varejista do estado de São Paulo. (Dissertação de Mestrado). Universidade Municipal de São Caetano do Sul, São Caetano do Sul, SP, Brasil.

Tomaél, M. I., \& Marteleto, R. M. (2006). Redes sociais: posições dos atores no fluxo da informação social nets: position of the actors in the information flow. Enc. Bibli. R. Eletr. Bibliotecon. Ci. Inf., n. esp.

Wellman, B., Haase, A. Q., Witte, J., \& Hampton, K. (2001). Does the internet increase, decrease, or supplement social capital? Social networks, participation and community. American Behavioral Scientist, 45(3), 436-455.

Withaker, F. (1993). Rede: uma estrutura alternativa de organização. CEDAC, 2(3).

Recuperado de

http://inforum.inSite.com.br/arquivos/2591/estrutura_alternativa_organizacao.PDF 